Insect Sense Organs", or "The Electron-microscopic Analysis of Secretion"). Incidentally, this last article emphasizes the difficulties of gaining any real concept of the sequence of events by studies of sectioned material only. In spite of much excellent microcinematography of cells (see the article by C. M. Pomerat on "Cinematography, Indispensable Tool of Cytology") the concept that granules in cells are a necessary part of the secretory process dies hard. Such activities as pinocytosis and the temporary storage of raw materials and the accumulation of metabolic by-products tend to be forgotten by many investigators of secretory processes when they are attempting to interpret the photographs of fixed sections. Similarly, if the vast array of surfaces and membranes, belonging to various parts of the endoplasmic reticulum, mitochondria and the like are really the sites for the production of secretions by chemical syntheses, the final products might never accumulate anywhere, but could be dispersed molecule by molecule into the tissue-fluids, ducts or bloodstream, just as and when they were produced. In a factory, storage is only necessary when production exceeds demand. Fleet Street can daily saturate the breakfast tables of Britain with only the minimum of storage in the printing works.

Books of the kind under review make invaluable reading for all biologists. New horizons are inevitably opened up to the reader, and the exploration of uncharted seas provides stimulating competition for the old-established and perhaps obsolete trade routes. Though some of the articles are more condensed than others, all are genuine reviews and not just annotated lists of references. As such they should appeal to all biologists who are concerned with how things work and not only to eytologists in the narrow sense.

E. N. WILLMER

\section{FACT AND SURMISE ON VIRUSES}

Advances in Virus Research

Vol. 8. Edited by Kenneth M. Smith and Max A. Lauffer. Pp. ix +414. (New York: Academic Press, Inc.; London: Academic Press, Inc. (London), Ltd., 1961.) $86 s$.

7 HE three main components of a science are: the methods used to make observations, the observations, and the interpretations based on them. The last merge smoothly into surmises, and the zone to which one label rather than the other is attached is clearly a matter of opinion. In the early days of virus research there was so little genuine information that interpretation made up an unusually large proportion of the whole. This seems to have established a tradition, and it is piously maintained by Kellenberger and by Mahler and Fraser in the articles on bacteriophage in this book. Each contains much valuable information, and the authors, as a rule, distinguish observation from surmise, but there is a risk that many readers will not keep the distinction continually in mind, in the face of such admirably persuasive presentations, and will get a false impression of the amount that is definitely known.

To redress the balance there is an article by Valentine on the enhancement of contrast in electron microscopy. This explains what is done, why it is done, and why alternative methods would be ineffective. After a general section on photographic contrast, the merits of different methods for varying the electron-stopping power of the specimen are discussed. This is followed by a comparison of the results achieved by 'staining' viruses with heavy atoms, by surrounding them with a film containing heavy atoms so that the viruses show up in 'negative contrast', and by Müller's technique of evaporating metal across the dry preparation from one side so that the viruses and their surface features cast shadows.

Cooper contributes an article on plaque assay of animal viruses. A thin layer of living susceptible cells is immobilized on the wall of a suitable vessel, either by allowing the cells to become attached or by embed. ding them in agar; the virus suspension is then spread over the surface. Plaques of infected cells develop and can be recognized either by direct observation or after staining. The method is formally identical with the plaque assay of bacteriophage on a plate covered with susceptible bacteria. It has now been applied to more than 50 viruses or virus strains and permits a precision and rapidity of work that was impossible with intact hosts or host tissues.

Mumps virus is in many ways similar to the influenza viruses, Newcastle disease virus, and the para-influenza viruses. Like these viruses it is absorbed by erythrocytes and agglutinates them, but its enzymatic activity, leading to release, is feeble. Cantell describes its biological properties, the difficulties met in attempts to purify it, and the variability of the response of hosts to it. There are surprising, and still unexplained, differences in even such a simple host as the egg allantoic membrane so that, at some seasons, it is almost impossible to work with the virus. This is experimentally inconvenient, but it is a salutary reminder that, in spite of the importance of information gained by physical methods, virus research remains a branch of biology.

There are three purely biological articles, McNair Scott discusses poliomyelitis, Coxsackie, and other viruses that characteristically attack intestinal and respiratory tissue. Bang and Luttrell discuss the nature of pathogenesis-that is, the relationship between host and parasite - in an extensive group of animal viruses. No generalizations emerge from this except the not unexpected one that any treatment which affects the metabolism of the host will affect the behaviour of some virus in it. Pereira has a similar theme: he is concerned with changes in individual infected cells and the light they throw on the mechanism of virus multiplication and on the reasons why this is so often harmful to the host.

This volume maintains the high standard of the series. It could be argued that the absence of an article dealing specifically with plant viruses makes the book unbalanced, but this should not lead those primarily interested in plant viruses to disregerd it for there is much here that, either by extension or analogy, will be of interest to them. N. W. Pirie

\section{EVERYDAY USES OF ATOMIC ENERGY}

The Release and Use of Atomic Energy

By Dr. T. E. Allibone. (Based on the Royal Institution Christmas Lectures.) Pp. xii $+158+20$ plates. (London: Chapman and Hall, Ltd., 1961.) 25s. net.

7 HIS book is based on the Christmas Lectures for young people which Dr. Allibone gave in 1960 at the Royal Institution. It follows the admirable tradition of those lectures in giving a clear and well- 